\title{
Mothers' concept of measles and attitudes towards the measles vaccine in Ile-Ife, Nigeria
}

\author{
A I ODEBIYI AND S C EKONG \\ From the Department of Sociology and Anthropology, University of Ife, Ile-Ife, Nigeria
}

SUMmaRY The attitude of Nigerian mothers, mainly Yoruba, towards measles vaccine and other aspects of prevention are influenced by different perceptions of the cause of measles. There is a significant correlation between the literacy of mothers and their belief in the efficacy of measles vaccine but not between their ages and belief. The mothers' perception of measles is a function of their socioeconomic characteristics, with the lower socioeconomic group tending more to define measles within the supernatural context. The findings indicate the necessity for health education to be based on local culture when promoting vaccination.

The gravity of measles as a cause of death is now being realised in Nigeria. Several authors ${ }^{1-5}$ have emphasised the seriousness of measles either as the most common reason for admission to children's units in Nigeria or as a major killer disease. Although mortality in many childhood diseases has generally declined, measles still deserves special attention because in 1973 it came second to pneumonia as a major cause of death in Nigeria with 1029 recorded deaths. $^{6}$ In that year Lagos State alone had 321 recorded deaths from measles.

In 1978 in Ogun State measles still headed the list of causes of mortality from communicable diseases diagnosed in all the hospitals in the State, with a total of 319 deaths. It also had the highest case fatality ratio of 4.05 deaths per 100 cases. $^{7}$ In Oyo State, where this study is based, measles is one of the four major causes of death resulting from notifiable diseases. ${ }^{8}$ All these data reflect only reported cases, for in Nigeria there is a great degree of underreporting, which is attributed to the effect of cultural factors and availability of alternative treatment. ${ }^{910}$ Many cases are not even brought to the hospital, and this further strengthens the need to study how aware mothers are of the gravity of measles as a cause of death. The high incidence of measles in children under 2 years has been attributed to some child-rearing habits in this country, such as the custom of strapping babies on the back, thus exposing them to droplet-borne infection, ${ }^{4}$ and of allowing older children to take charge of and play with infants. ${ }^{1}$

In Ile-Ife town one-quarter of the children in the classes for the handicapped (run by the Oyo State
Government, Ministry of Education) are victims of measles. They are either blind, deaf, and dumb after the measles attack or they were born with such handicaps because their mothers had German measles (rubella) during pregnancy (E Balogun, unpublished observation). This tends to support Hendrikse ${ }^{12}$ who observed that a high proportion of children who had survived measles show pronounced debility for a long time after the illness.

In this study, therefore, we proposed to conduct an in-depth interview into mothers' awareness of the seriousness of the disease and their knowledge of its prevention. Specifically, we wanted to know: (1) whether they were aware of the measles vaccine that is usually given to children aged from 9 to 12 months to prevent measles; (2) were their children immunised, (3) what was their general belief or feelings as regards the vaccine, (4) what alternatives did they have to prevent measles, and (5) what was their concept of measles.

\section{Methods}

We first used an areal probability sampling technique. The areal units were defined by grid squares superimposed on a map covering Ile-Ife town. A total number of 50 grid squares were listed excluding those areas on the outskirts that had no settlements. This constituted our frame, listing all the squares in the population. From these, 10 squares were randomly selected. Each of the 10 squares was divided up into blocks, a block being a rectangular or polygonal piece of land bounded by identifiable streets. To obtain these blocks, the interviewers 
travelled around each of the squares to identify the streets. By using a systematic sample, one out of every two blocks was selected from each square, and the "eligible" households in the selected blocks were listed. An eligible household was defined as follows: all those dependent on a common or pooled income living under the same roof and eating from the same pot. They need not necessarily be related to each other by blood or marriage. If they usually slept and ate in the same house with domestic and economic ties, they constitute a household-that is, families and their dependents such as domestic helps; but all single people who were financially independent of any family group, living in a separate house or room-that is, spinsters and bachelors-were excluded because they did not fit into this study on child care. Although these $\mathbf{1 0}$ selected grid squares were not known to contain an equal number of elements, the pilot study indicated that an average area unit had about 400 eligible households. (The total number of eligible households in each of the 10 squares ranged from 392 to 404 .) We thus decided on an equal sample size of 20 households a square. These 20 households in each square were obtained through a systematic sampling technique in which we used the lists of eligible households compiled for each square. From each list, the first household was randomly selected from the first 20 households, and every twentieth household thereafter was selected. From the 20 households thus selected, we interviewed the oldest mother in each selected household. (We chose the oldest mother because of her years of experience with childrearing, childhood diseases and their management, and also because her own decision and methods are paramount within any family in Nigeria.) Altogether 200 mothers were interviewed during April and May 1980.

\section{Results and analysis of data}

In Nigeria, as in most developing countries, the germ theory as a cause of disease has not yet been widely accepted. ${ }^{\text {13-15 }}$ People have different ways of defining diseases and looking at health matters. Their concept of disease tends to affect the mode or channel used to treat or prevent disease. Of the $\mathbf{2 0 0}$ mothers interviewed, 181 were Yoruba. Because Ile-Ife is a university town, however, a few expatriates reside in Ife town because of a shortage of accommodation within the university campus itself. Altogether 141 were Christians, 47 professed the Islamic faith, 11 believed in the traditional religion, while one respondent claimed that she did not belong to any form of religious grouping.

Thirty-one were in the professional group such as doctors, nurses, teachers, lecturers, and administrators but most mothers were petty traders. There were 103 non-literate mothers, 37 who had had only primary education, 47 intermediate education, and 13 university education. These graduates would account for only part of the professional group, however, and some teachers, for none of the nurses were university graduates.

When these women were asked their views about the measles vaccine, 54 believed implicitly in the efficacy of the vaccine, 112 did not believe in the vaccine as a preventive measure, and the remaining 34 had no knowledge of the vaccine (table 1). The non-believers in the measles vaccine were asked to explain their attitudes. How had they evaluated the efficacy of the vaccine? Some of their responses were based on the experiences of their children with the vaccine, while other responses were motivated by what they had heard from friends, relatives, and neighbours about the vaccine. Eighty-one believed that the vaccine is not preventive because they claimed that some of their children who had been immunised still contracted measles in later years. This is contrary to the findings by Krugman et al, ${ }^{16}$ who reported that in their study 23 of 46 children in a building were given measles vaccine. When an epidemic of measles occurred in the building seven weeks later all 23 vaccinated patients were solidly protected, while among the 23 unvaccinated controls the 17 who were infected gave no evidence of contact infection from exposure to the immunised group. This finding has been further corroborated by Black and Yannet. ${ }^{17}$ Both these studies, however, relate to children in the US, who are in a totally different setting of questionable relevance to contact conditions and states of health in Nigeria. Nevertheless, the mothers' claim in this study that their children still contracted measles after they have had the vaccine needs further investigation and intensive research.

Nine mothers, who based their judgment on past experience, claimed that the vaccine was dangerous and harmful to infants, "It makes the baby sick." This tends to conform with reports 121819 that the vaccine does have some dangerous side effects, for they have actually discussed the vaccine in relation to encephalitis and convulsion. The type of vaccine

Table 1 Attitudes of mothers to the measles vaccine

\begin{tabular}{lr}
\hline Responses & No of women \\
\hline It is preventive & 54 \\
It is not preventive & 81 \\
It is harmful to infants & 9 \\
Baby should develop natural immunity & 1 \\
Measles vaccine must be combined with traditional medicine & 21 \\
No knowledge of the vaccine at all & 34 \\
Total & 200 \\
\hline
\end{tabular}


used, however, is important, for the study of Morley et $a l^{18}$ and that of the MRC ${ }^{19}$ related to the killed vaccine. Those mothers still guided by experience included the 21 who claimed that the vaccine is effective only when combined with traditional medicine, such as keeping tagiri (Adenopus breviflorus) in the house during the dry season. Only one mother claimed that she would prefer that her babies should contract measles and develop their own natural immunity towards the disease. This response was from an educated mother who believed that an attack of natural measles confers a life-long immunity. This accords with the WHO report ${ }^{20}$ that the immunity appearing after vaccination with attenuated measles vaccine is equivalent to that obtained after natural measles. Thus the mothers have either had experience with the vaccine and formed an attitude towards it or they have been socially influenced to maintain a negative attitude. It is obvious from the foregoing analysis that many mothers have had unsuccessful experiences with the vaccine. This raises some important issues. For it would be interesting to know from these mothers (1) at what age the child was immunised, (2) how many years after the immunisation did the child have measles, (3) what type of vaccine was used, (4) if the child was ill after vaccination, what symptoms were observed, etc. This tends to highlight another area of research which would be adequately dealt with in a subsequent paper.

The 166 mothers in the study who knew of the vaccine and had either negative or positive attitudes toward it were further analysed in terms of their socioeconomic characteristics to ascertain the roles of these factors in influencing their beliefs about the vaccine. For income and preventive behaviour are positively related, ${ }^{25}$ the higher the income level of a group, the more will they follow recommended preventive or diagnostic recommendations. Other authors ${ }^{22-28}$ have associated socioeconomic status with states of health and preventive behaviour, and those in the lower socioeconomic groups have been observed to have negative attitudes towards preventive medicine and preventive behaviour. When the literacy level was correlated with beliefs in the measles vaccine (table 2 ), $\chi^{2}$ was significant, thus indicating that the literacy level of the mothers is

Table 2 Literacy of mothers and beliefs in the measles vaccine

\begin{tabular}{llcc}
\hline Education & Believe & Do not believe & Total \\
\hline Literate & 38 & 35 & 73 \\
Non-literate & 16 & 77 & 93 \\
Total & 54 & 112 & 166 \\
\hline
\end{tabular}

Thirty-four mothers who had no knowledge of the measles vaccine were excluded $\left(x^{2}=21 \cdot 20, p<0.001\right)$. influential in determining the types of beliefs held about the vaccine. Yet almost half the literate mothers did not believe in the vaccine, perhaps because of detrimental information about the vaccine or because it had failed them on some occasion. Some of these literate mothers claimed that the vaccine made the attack very mild, although the vaccine had not prevented the attack as it should. That 77 out of 93 non-literate mothers did not believe in the measles vaccine is disheartening, for it shows that children from the socioeconomically disadvantaged groups who needed the vaccine most were not getting it, especially as there is much evidence that measles now, as in the past, is more frequent in the lower socioeconomic groups. ${ }^{27} 28$

When the occupational status of the mothers was correlated with the beliefs held about the vaccine (table 3), the proportion of mothers in the higher occupational group who believed in the efficacy of the vaccine (53\%) was significantly higher than the proportion in the lower occupational group (19\%). This supports the generally held view that those on the higher socioeconomic rung of the ladder will tend to have positive attitudes towards preventive behaviour compared with those on the lower economic level. In this case they tend to believe more in the measles vaccine as a preventive measure against the attack.

The mothers' belief about the vaccine was correlated with their age (table 4). Those under 40 were classified as "young" while those aged 40 and over were classified as "old." Here again the proportion of young mothers who believed in the efficacy of the vaccine was significantly higher than

Table 3 Occupational status of mothers and beliefs about the measles vaccine

\begin{tabular}{llcc}
\hline Status of respondents & Believe & Do not believe & Total \\
\hline $\begin{array}{l}\text { Higher occupational status: } \\
\text { professional, white collar, }\end{array}$ & 35 & 31 & \\
$\begin{array}{l}\text { and skilled } \\
\text { Lower occupational status: }\end{array}$ & & & 66 \\
$\begin{array}{l}\text { unskilled, traders, } \\
\text { unemployed }\end{array}$ & 19 & 81 & 100 \\
Total & 54 & 112 & 166 \\
\hline
\end{tabular}

Thirty-four mothers who had no knowledge of the vaccine were excluded $\left(x^{2}=20.9, p<0 \cdot 001\right)$.

Table 4 Age of mothers and their beliefs in the measles vaccine

\begin{tabular}{llcc}
\hline Age & Believe & Do not believe & Total \\
\hline Young $(<40)$ & 40 & 52 & 92 \\
Old $(\geqslant 40)$ & 14 & 60 & 74 \\
Total & 54 & 112 & 166 \\
\hline
\end{tabular}

Thirty-four mothers who had no knowledge of the vaccine were excluded $\left(x^{2}=11, \mathrm{p}<0.001\right)$. 
the proportion of the old mothers who had this same belief. This tends to support previous studies that asserted that the young tend to use modern medical treatment more than their older counterparts. ${ }^{29} 30$

As a result of the lack of faith that most mothers expressed we were prompted to probe further into any alternative preventive measures taken. Apart from the 54 mothers who believed in the efficacy of the vaccine, all the other mothers were asked to state the preventive measures taken against measles. This category of mothers included those who did not even have any knowledge of the vaccine, for it would be interesting to know their precautions. This, however, excluded one educated mother who claimed that she does not take any preventive measure. She prefers that her children should have measles and develop natural immunity against it.

The most frequently cited preventive measure, which is undertaken in the dry season when the disease reaches its peak, is that of bathing and rubbing the body with some herbal preparation. A certain amount of this herbal mixture is also drunk daily. This practice is followed by those who believe in keeping tagiri in the house during this period. This fruit, which looks like melon, is supposed to be kicked or swept about the house throughout the dry season. Next were those who believed in a combination of the vaccine with the traditional therapy of keeping tagiri in the house during the dry weather. Then came those who believed in disinfecting the house with palm wine combined with the regular drinking of this wine during the dry season. There were also those who still believed in the wearing of rings and use of charms, prayers, and use of holy water.

A close analysis of these preventive measures, empasises that the Yoruba concept of measles is within the supernatural realm. Indeed, most mothers associated it with Sonponna (the god of the smallpox). They claimed that as a result of this connection there is some similarity in terms of the victims being marked with spots after a serious attack of either of the ailments. This point was mentioned by Maclean $^{31}$ in relation to smallpox "oba ti ko" meaning "the god has marked him."

Of all the 200 mothers interviewed, only 60 claimed that measles is due to a natural cause. Table 5 shows that 77 claimed it to be due to a supernatural cause while 22 tend to attribute it to both natural and supernatural causes. These claimed that natural causes may be concerned, but external forces tend to determine the severity of the attack and the degree of prominence of the spots. The remaining 41 had no idea as to the cause of the disease, they knew only that it tends to occur in the dry season, but they were not aware of what factors could be responsible. We then correlated mothers' beliefs about causes with their socioeconomic characteristics (table 5). In terms of the literacy level of mothers and their beliefs about causation $\chi^{2}=69.6, p<0.001$ and in terms of the occupational status of mothers and their beliefs about the cause of measles $\chi^{2}=95, p<0.001$. In other words more of the literate mothers tended to define measles within the natural realm. In fact 93.3\% of those who attributed measles to a natural cause were literate. The same pattern was maintained by the mothers with higher occupational status. For here, too, a significantly higher proportion knew the cause of measles as against the proportion of the lower occupational groups who knew the cause. This confirms earlier findings about the concept of diseases among various groups in Ibadan, Nigeria. ${ }^{9} 18$

As long as people define disease within the supernatural context, they will be reluctant to use scientific preventive measures which do not placate the offended spirits. Seventy per cent of the mothers interviewed did not know the scientific cause of measles. This high figure tends to correspond with the findings of Ogunmekan, ${ }^{27}$ for in his Lagos study of 141 mothers, $93.6 \%$ did not know the cause of measles. Obviously, much is urgently required by way of health education in this country to enlighten the public about the cause, treatment, and prevention of measles.

Table 5 Distribution of mothers' responses about the aetiology of measles cross-tabulated with the mothers socioeconomic characteristics

\begin{tabular}{|c|c|c|c|c|}
\hline \multirow[b]{3}{*}{ Responses about aetiology } & \multirow{2}{*}{\multicolumn{2}{|c|}{ Mothers' level of literacy }} & \multicolumn{2}{|c|}{ Mothers' occupational status } \\
\hline & & & \multirow{2}{*}{$\begin{array}{l}\text { Higher: } \\
\text { professional, } \\
\text { white collar, } \\
\text { skilled }\end{array}$} & \multirow{2}{*}{$\begin{array}{l}\text { Lower: } \\
\text { unskilled, } \\
\text { traders, } \\
\text { unemployed }\end{array}$} \\
\hline & Literate & Non-literate & & \\
\hline $\begin{array}{l}\text { Natural cause } \\
\text { Supernatural cause } \\
\text { Both natural and supernatural } \\
\text { Don't know the cause } \\
\text { All mothers }\end{array}$ & $\begin{array}{r}56 \\
21 \\
9 \\
11 \\
97\end{array}$ & $\begin{array}{r}4 \\
56 \\
13 \\
30 \\
103\end{array}$ & $\begin{array}{r}51 \\
9 \\
6 \\
4 \\
70\end{array}$ & $\begin{array}{r}9 \\
68 \\
16 \\
37 \\
130\end{array}$ \\
\hline
\end{tabular}

$x^{2}=89.6, \mathrm{p}<0.001, \mathrm{df}=3$.

$x^{2}=95, \mathrm{p}<0.001, \mathrm{df}=3$. 


\section{References}

${ }^{1}$ Omololu A. Child health in Western Nigeria. West Afr Med J 1965; 14: 255-68.

${ }^{2}$ Gans B, MacNamara FN, Morley DC, Thomson SW, Watt A. Some observations on the epidemiology of measles in West Africa. West Afr Med J 1961; 16: 253-62.

${ }^{3}$ Morley D. Measles in Nigeria. Am J Dis Child 1962; 103: 230-5.

'Morley D, MacWilliams E. Measles in a Nigerian community. West Afr Med J 1961; 10: 246-53.

${ }^{5}$ Smith EA, Foster SO. The effect of the smallpox eradication measles control programme on measles admission to the Lagos Infectious Disease Hospital, Yaba, Nigeria. West Afr Med J 1970; 19: 51-6.

- Federal Office of Statistics. Annual abstract of statistics. Lagos: FOS, 1975: 177.

${ }^{7}$ Ministry of Finance and Economic Development, Statistics Division. A summary of current medical and health statistics. Abeokuta, Ogun State, Nigeria: MFED, 1978: 2.

'Ministry of Finance and Economic Development, Statistics Division. Annual digest of medical and health statistics. Ibadan, Oyo State, Nigeria: MFED, 1976: 55.

${ }^{9}$ Edington GM, Odebiyi AI. Cancer and ageing in Ibadan: a sociological analysis. Soc Sci Med 1976; 10: 477-81.

${ }^{10}$ Odebiyi AI. Socio-cultural factors affecting health care delivery in Nigeria. Tropical Medicine and Hygiene 1977; 80: 249-54.

${ }^{12}$ Hendrikse RG, Montefiore D, Sherman P, Van Der Wall $H M$. Studies in measles vaccination in Nigerian children. Br Med J 1964; ii: 470-4.

${ }^{13}$ Erinosho $O$. Notes on the concept of disease and illness: the case of the Yoruba in Nigeria. Nigerian Journal of Economic and Social Studies 1976; 18: 471-6.

${ }^{14}$ Prince R. Indigenous Yoruba psychiatry. In: Kiev A, ed. Magic, faith and healing. New York: The Free Press, 1974: 84-120.

15 Odebiyi AI. Socio-economic status, illness behaviour and attitudes towards disease aetiology in Ibadan. Nigerian Behavioural Science Journal 1980; 3: 172-85.

16 Krugman S, Giles JP, Jacobs AM. Studies on an attenuated measles virus vaccine. VI Clinical antigenic and prophylactic effects in institutionalised children. $N$ Eng J Med 1960; 263: 174-7.
${ }^{17}$ Black FL, Yannet $H$. Inapparent measles after gammaglobulin administration. JAMA 1960; 173: 1183-8.

${ }^{18}$ Morley D, Woodland M, Martin WJ. Measles in Nigerian children. J Hyg 1963; 61: 115-33.

${ }^{19}$ Measles Vaccine Committee, Medical Research Council. Vaccination against measles: a study of clinical reactions and serological responses of young children. $\mathrm{Br} \mathrm{Med} J$ 1965; ii: 817-23.

${ }^{20}$ World Health Organisation. Measles vaccines. Technical Report Series 1963; No 263: 6-37.

${ }^{21}$ Rosenstock IM. Prevention of illness and maintenance of health. In: Kosa J, Antonovsky A, Zola IK, eds. Poverty and Health. Cambridge, Massachusetts: Harvard University Press, 1969: 173.

${ }^{22}$ Okediji FO. Some social psychological aspects of fertility among married women in an African city. Nigerian Journal of Economic and Social Studies 1969; 9: 67-72.

${ }^{23}$ Olusanya PO. The educational factor in human fertility: a case study of the residents of a sub-urban area in Ibadan, Western Nigeria. Nigerian Journal of Economic and Social Studies 1967; 9: 351-74.

${ }^{24}$ Caldwell JC, Igun A. The spread of antenatal knowledge and practice in Nigeria. Population Studies 1970; 24: 6-10.

${ }^{25}$ Koos EL. The health of regionville. New York: Columbia University Press, 1954.

${ }^{26}$ Kadushin C. Social class and the experience of ill health. Journal of Health and Human Behaviour 1962; 3: $30-40$.

${ }^{27}$ Ogunmekan DA. The socio-economic factors influencing the utilization of health services in Nigeria. In: Akeredolu-Ale A, ed. Proceeding of the Conference on Social Research and National Development in Nigeria. Ibadan: Nigerian Institute of Economic and Social Research, University of Ibadan, 1975, II: 934-47.

${ }^{28}$ Halmers, 1.908. Quoted in Morley DC. Measles round the world. Maternal and Child Care 1966; 2: 207-15.

${ }^{29}$ Maclean U. Cancer surveys in developing African countries with special reference to Ibadan, Western Nigeria. Edinburgh: University of Edinburgh, 1965: 348. (MD thesis.)

${ }^{30}$ Maclean U. Social and community medicine for students. London: William Heinemann Medical Books Limited, 1971. 